\title{
PARTIÇÃO DE PROTEÍNAS DO SORO DE LEITE EM SISTEMAS DE DUAS FASES COMPOSTOS POR LÍQUIDOS IÔNICOS
}

\author{
M. T. NEVES ${ }^{1}$, A. A. BALBUENO ${ }^{1}$, M. P. MIRANDA ${ }^{1}$, D. COLOSIMO ${ }^{1}$, R. C. S. SOUSA ${ }^{1}$ e G. \\ T. DUTRA ${ }^{1}$
}

${ }^{1}$ Universidade Federal de Viçosa, Departamento de Química e Engenharia Química E-mail para contato: rita.sousa@ufv.br

\begin{abstract}
RESUMO - Os líquidos iônicos (LI) são sais compostos por íons grandes que não formam uma rede cristalina bem definida, e assim permanecem líquidos à temperatura ambiente ou perto desta. Estes compostos apresentam características "verdes", como a volatilidade desprezível, não-inflamabilidade em condições ambiente, estabilidade térmica e química elevada e grande capacidade de solvatação e despertam especial interesse em aplicações na separação e purificação de biomoléculas. Sistemas aquosos bifásicos baseados em LI foram utilizados neste trabalho para estudar a partição de glicomacropeptídeo (GMP) e beta-lactoglobulina $(\beta-\lg )$ do soro de leite. $O$ efeito da concentração de líquido iônico $\left(\mathrm{C}_{4} \mathrm{minCl}\right)$ na eficiência de extração foi investigado. Resultados experimentais mostraram que $62,5 \%$ de GMP e $98,4 \%$ de $\beta$-lg foram extraídos para a fase superior (rica em LI) indicando que esta nova técnica é promissora para extração de ambas as proteínas.
\end{abstract}

\section{INTRODUÇÃO}

A técnica de extração líquido-líquido é muito utilizada nos processos de separação e purificação de biomoléculas, No entanto, as biomoléculas, tais como as proteínas, organelas e fragmentos celulares, podem sofrer danos irreparáveis quando submetidas a esse processo, no caso do uso tradicional de solventes orgânicos. Logo, o processo utilizando sistemas aquosos bifásicos (SAB) apareceram como uma técnica alternativa para a purificação de proteínas (Pessoa Jr. e Kilikian, 2005). Este processo possui diversas vantagens já que é um sistema econômico e eficiente, possui curto tempo de processo, baixo consumo de energia e possibilidade de aplicação em grande escala (Ventura et al., 2011; 2009).

Os SAB se formam quando um polímero solúvel em água e uma substância de baixo peso molecular (normalmente um sal inorgânico) ou dois tipos de polímeros solúveis em água se dissolvem em solução aquosa acima de suas concentrações críticas (Liu et al., 2011). No entanto, a maioria dos polímeros utilizados nos SAB convencionais apresenta alta viscosidade (Perumalsamy et al., 2007) e as soluções que são formadas são, geralmente, opacas, atrapalhando as análises dos compostos extraídos do sistema. Com isso, hoje se utiliza os líquidos iônicos (LI) em substituição a esses polímeros. Essa substituição oferece vantagens ambientais devido à baixa volatilidade dos LI e facilidade de reciclagem.

Os LI são sais compostos por íons grandes que não formam uma rede cristalina bem 
definida, e assim permanecem líquidos à temperatura ambiente ou perto desta. Esses compostos são considerados os novos tipos de "solventes verdes" já que têm propriedades únicas, tais como: são não-inflamáveis, pressão de vapor negligenciável, forte poder de solubilização e estabilidade química e térmica (Wei e Ivaska, 2008).

Considerando o alto valor nutricional, funcional e tecnológico das proteínas do soro de leite é interessante o estudo de seu uso e aproveitamento de seus componentes. Logo, os SAB com LI aparecem como uma técnica potencial para este fim. Portanto neste trabalho, foi estudar a extração das proteínas beta-lactoglobulina ( $\beta$-lg) e glicomacropeptídeo (GMP), presentes no soro de leite, em sistemas aquosos bifásicos constituídos pelo cloreto de 1-butil-3-mitelimidazólio $\left(\mathrm{C}_{4} \mathrm{mimCl}\right)$, água e sal inorgânico fosfato de potássio.

\subsection{Proteínas do soro de leite}

A produção de queijos e derivados do leite vem aumentando ao longo dos anos e, consequentemente, a produção de soro também vem aumentando e, em 2010 foi estimada na ordem dos 160 milhões de toneladas por ano (Magalhães et al., 2010). Devido a sua natureza perecível, o soro tem se tornado um problema crescente de poluição ambiental de rios, esgotos e oceanos, ele é considerado altamente poluente, apresentando um potencial poluidor muito maior do que o esgoto doméstico (Porto et al., 2005). É estimado que para cada quilo de queijo produzido, são gerados nove quilos de subprodutos com alta concentração de matéria orgânica (Faria et al., 2004).

As proteínas do soro correspondem a $20 \%$ das proteínas do leite e possuem várias propriedades, tais como: atividade hidratante, emulsificante, espumante, além de formar géis protéicos. As principais proteínas presentes, representando cerca de $90 \%$ das proteínas do soro, são a beta-lactoglobulina ( $\beta$-lg), a alfa-lactoalbumina ( $\alpha$-la) e o glicomacropeptídeo (GMP).

A $\beta$-lactoglobulina ( $\beta$-lg) é a proteína presente em maior quantidade no soro de leite bovino (cerca de $50 \%$ ) destacando-se por suas propriedades nutricionais e propriedades funcionais de grande aplicação na indústria de alimentos, como capacidade de emulsificação, formação de espuma/retenção de ar, geleificação, ligação de aroma e sabor, formação de filmes e cápsulas protetoras (Fox, 2001).

O glicomacropeptídeo (GMP) atua na regulação de respostas imunológicas; na diminuição da secreção gástrica; anti-hipertensivo, ação protetora contra agentes condicionadores de problemas cardiovasculares; na diminuição do apetite; na inibição da adesão de microrganismos em polímeros, sugerindo o uso do GMP como inibidor de placas bacterianas e de cáries dentárias; estabilidade frente ao calor, solubilidade em condições ácidas (Neeser et al., 2000; El-Salam et al., 1996; Idota et al., 1994). O glicomacropeptídeo é um peptídeo derivado da caseína que corresponde de 10 a $20 \%$ do total de proteínas do soro de leite. O GMP é um dos peptídeos bioativos do soro resultante da produção de queijos pela via da renina (Dziuba e Minkiewicz, 1996). 


\subsection{Sistemas aquosos bifásicos (SAB)}

Os Sistemas Aquosos Bifásicos (SAB) são definidos, genericamente, como sistemas de duas fases líquidas imiscíveis em que o solvente principal é a água (Zaslavsky, 1995). Eles se formam quando um polímero solúvel em água e uma substância de baixo peso molecular (normalmente um sal inorgânico) ou dois tipos de polímeros solúveis em água se dissolvem em solução aquosa acima de suas concentrações críticas (Liu et al., 2011). As duas fases aquosas são formadas com diferentes composições. Os solutos distribuem-se entre as duas fases de acordo com sua afinidade relativa com cada fase (Ventura et al., 2011).

Em geral, os SAB apresentam grande quantidade de água em ambas as fases, fazendo com que sejam meios muito pouco agressivos a moléculas como enzimas, por exemplo. Cada tipo de $\mathrm{SAB}$ (polímero e sal ou dois polímeros) tem, normalmente, aplicações diferentes em termos das substâncias a serem purificadas e as necessidades operacionais. Os primeiros tendem a serem menos viscosos, facilitando a separação das fases, enquanto o segundo pode ser aplicável a substâncias que não toleram a presença de sais em concentrações maiores que, por sua vez, apresentam também maiores dificuldades quanto à reciclagem ou descarte (Monteiro Filho, 2010).

Os SAB são reconhecidos como sistemas econômicos e eficientes e oferecem muitas vantagens como: curto tempo de processo, baixo consumo de energia e possibilidade de aplicação em grande escala. Além disso, têm sido muito utilizados na recuperação e purificação de proteínas (Ventura et al., 2011; 2009).

\subsection{Líquidos iônicos}

A maioria dos polímeros utilizados nos SAB convencionais apresenta alta viscosidade (Perumalsamy et al., 2007), logo, as soluções que são formadas são, geralmente, opacas. Isto pode atrapalhar nas análises dos compostos extraídos do sistema. Com isso, nos últimos anos o estudo da utilização de SAB baseados em líquidos iônicos (LI), constitui uma área emergente e que está em franco crescimento, com um grande potencial como possíveis substitutos para os solventes orgânicos convencionais. Os LI têm sido aplicados em processos de biopurificação e bio-extração e é possível observar que sua aplicação melhora a estabilidade da enzima e a seletividade do substrato e/ou produto (Welton, 1999).

Os LI são sais compostos por íons grandes, um cátion orgânico relativamente grande e um ânion orgânico ou inorgânico relativamente pequeno, que não formam uma rede cristalina bem definida, e assim permanecem líquidos à temperatura ambiente ou perto desta. Eles apresentam uma fraca interação interiônica, a qual resulta em uma baixa energia do retículo cristalino e baixa temperatura de fusão, o que os difere dos sais comuns (Cassol, 2007). Considerados os novos tipos de "solventes verdes", os LI têm propriedades únicas, tais como: são não-inflamáveis, pressão de vapor negligenciável, forte poder de solubilização e estabilidade química e térmica (Wei e Ivaska, 2008). Eles têm aplicação química e bioquímica incluindo sínteses químicas, transformações biocatalíticas, projetos de dispositivos eletroquímicos e processos de separação (Pandy, 2006; Wasserscheid e Welton, 2003).

A literatura mostra que os pesquisadores que testaram os SAB baseados em LI obtiveram 
bons resultados na extração de biomoléculas (Ventura et al., 2011; Claudio et al., 2010; Pei et al., 2009; Du et al., 2007. No entanto, há ainda pouco estudo a respeito do comportamento de partição de proteínas do soro de leite ( $\beta$-lg e GMP) em SAB baseados em LI.

Assim, neste trabalho foi feito um estudo envolvendo o $\mathrm{LI} \mathrm{C}_{4} \mathrm{minCl}$ a fim de se obter novas informações acerca da capacidade de promoverem a formação de $\mathrm{SAB}$ e extraírem proteínas do soro do leite, visando a recuperação destas proteínas com alto valor agregado e a diminuição do impacto ambiental causado pelo descarte inadequado do soro.

\section{MATERIAL E MÉTODOS}

No experimento foram utilizados o líquido iônico cloreto de 1-butil-3-metilimidazólio $\left(\mathrm{C}_{4} \mathrm{mimCl}\right)$, adquirido da Sigma Aldrich e as proteínas $\beta-\lg$ e GMP, adquiridas da DAVISCO Food Ingredientes International (Eden Praire, EUA). Para a formação do sistema, utilizou-se juntamente com os líquidos iônicos, o sal inorgânico, fosfato de potássio (VETEC) e água deionizada. Os diagramas de equilíbrio foram obtidos em literatura (Neves, 2009). As concentrações utilizadas para o $\mathrm{C}_{4} \mathrm{mimCl}$ foram: $15,75 \%, 17,69 \%$ e $21,36 \%(\mathrm{~m} / \mathrm{m})$. A massa total dos sistemas preparados foi de 10 gramas. A massa de GMP utilizada foi de 0,02 gramas e de $\beta-1 \mathrm{~g}$ foi de 0,01 gramas.

Os sistemas foram preparados em tubos de centrífuga graduados e calibrados. Em cada sistema eram pesados sequencialmente o fosfato de potássio, a água, proteína e o líquido iônico (BEL Engineering, M 214 A). Após a preparação, os SAB foram centrifugados (FANEM, Excelsa II 206 BL) a 3500 x g por 6 minutos e, então, deixados em repouso por aproximadamente 12 horas em estufa (FANEM, 502) a temperatura de $25{ }^{\circ} \mathrm{C}$, para que o equilíbrio fosse atingido. Após alcançado o equilíbrio, o volume e a altura de cada fase foram medidos. Uma alíquota de cada uma das fases resultante foi coletada com o auxílio de uma seringa.

A determinação da concentração de proteína nas fases foi feita em espectrofotômetro (Agilent, 8453) a $280 \mathrm{~nm}$ para os sistemas com a $\beta$-lg e a $240 \mathrm{~nm}$ para o GMP. O coeficiente de partição da razão entre as concentrações de proteína na fase superior e inferior.

$$
K=C_{\text {sup }} / C_{\text {inf }}
$$

onde $\mathrm{C}_{\text {sup }}$ e $\mathrm{C}_{\text {inf }}$ representam, respectivamente, a concentração da proteína na fase superior (rica em LI) e na fase inferior (rica em sal inorgânico).

Para selecionar os SAB com a melhor capacidade de purificação das proteínas, foi calculada uma recuperação teórica (y, \%) na fase superior por meio da seguinte equação:

$$
y_{\text {sup }}(\%)=100 /[1+(1 / R . K)]
$$

sendo $\mathrm{R}$ a razão entre os volumes da fase superior e inferior do sistema SAB em estudo. 


\section{RESULTADOS E DISCUSSÃO}

\subsection{Preparo dos SAB}

De acordo com dados de equilíbrio encontrados em literatura foram obtidas as massas necessárias de cada componente do sistema para a formação de fases. Nas Tabelas 1 e 2 são apresentadas as massas de água, LI, sal e proteína ( $\beta$-lg ou GMP) para cada sistema em estudo.

Tabela 1 - Composição mássica dos SAB para diferentes valores de concentração do LI, visando a partição de $\beta-\lg$

\begin{tabular}{|c|c|c|c|c|}
\hline Concentração LI $(\% \mathrm{~m} / \mathrm{m})$ & $\mathrm{m} \mathrm{sal}(\mathrm{g})$ & $\mathrm{m}$ água $(\mathrm{g})$ & $\mathrm{m} \mathrm{LI}(\mathrm{g})$ & $\mathrm{m} \beta-\lg (\mathrm{g})$ \\
\hline $18,00 \%$ & 3,231 & 6,609 & 2,160 & 0,01 \\
\hline $20,00 \%$ & 2,981 & 6,618 & 2,400 & 0,01 \\
\hline $22,00 \%$ & 2,484 & 6,636 & 2,880 & 0,01 \\
\hline
\end{tabular}

Tabela 2 - Composição mássica dos SAB para diferentes valores de concentração do LI, visando partição de GMP

\begin{tabular}{|c|c|c|c|c|}
\hline Concentração LI $(\% \mathrm{~m} / \mathrm{m})$ & $\mathrm{m} \mathrm{sal}(\mathrm{g})$ & $\mathrm{m}$ água $(\mathrm{g})$ & $\mathrm{m} \mathrm{LI}(\mathrm{g})$ & $\mathrm{m} \mathrm{GMP}(\mathrm{g})$ \\
\hline $15,75 \%$ & 2,267 & 6,138 & 1,575 & 0,02 \\
\hline $17,69 \%$ & 2,154 & 6,057 & 1,769 & 0,02 \\
\hline $21,36 \%$ & 2,304 & 5,540 & 2,136 & 0,02 \\
\hline
\end{tabular}

\subsection{Determinação do coeficiente de partição de beta}

A Tabela 3 apresenta os valores de $\mathrm{K}$ e de recuperação teórica para $\beta$-lg nos SAB baseados no $\mathrm{LI}\left(\mathrm{C}_{4} \mathrm{minCl}\right)$ e no sal fosfato de potássio.

Tabela 3 - Partição de $\beta$-lg em SAB

\begin{tabular}{|c|c|c|}
\hline Concentração LI $(\% \mathrm{~m} / \mathrm{m})$ & Coeficiente de partição $(\mathrm{K})$ & Recuperação teórica (\%) \\
\hline $18,00 \%$ & 21,51 & 94,58 \\
\hline $20,00 \%$ & 37,05 & 97,41 \\
\hline $22,00 \%$ & 40,87 & 98,39 \\
\hline
\end{tabular}

Verificou-se que uma maior concentração de LI promoveu uma maior partição da proteína para fase superior dos $\mathrm{SAB}$. Os pontos isoelétricos das proteínas usadas neste estudo são 3,8 para GMP e 5,2 para $\beta$-lg (Sgarbieri, 2004). Nos experimentos de extração, o pH do sistema foi de 6,8. Assim, a carga líquida de ambas as proteínas seria negativa e a interação entre o cátion imidazólio é, provavelmente, a força motriz para a extração (Pei et al., 2009). 


\subsection{Determinação do coeficiente de partição de GMP}

A Tabela 4 apresenta os valores de $\mathrm{K}$ e de recuperação teórica para GMP nos SAB baseados no $\mathrm{LI}\left(\mathrm{C}_{4} \mathrm{minCl}\right)$ e no sal fosfato de potássio.

Tabela 4 - Partição de GMP em SAB

\begin{tabular}{|c|c|c|}
\hline Concentração LI $(\% \mathrm{~m} / \mathrm{m})$ & Coeficiente de partição $(\mathrm{K})$ & Recuperação teórica $(\%)$ \\
\hline $15,75 \%$ & 3,787 & 73,773 \\
\hline $17,69 \%$ & 1,187 & 51,816 \\
\hline $21,36 \%$ & 0,422 & 28,985 \\
\hline
\end{tabular}

Os valores de $\mathrm{K}$ encontrados foram similares a outros trabalhos reportados na literatura. Chen (1992) estudou a partição e separação das proteínas $\alpha$-la e $\beta$-lg em PEG (polietilenoglicol) utilizando um SAB com fosfato de potássio e obteve valores de coeficiente de partição na faixa de 1 a 7. Mokhtarani et al. (2011) também estudaram a partição das mesmas proteínas em SAB de polivinilpirrolidona e fosfato de potássio e obtiveram valores dentro da faixa de 1 a 7 . Silva et al. (2009), em seu artigo de partição da proteína GMP em sistemas aquosos de duas fases compostos por polímero (PEG) e sal, obtiveram valores de $\mathrm{K}$ dentro da faixa de 2 a 9.

Observou-se que o coeficiente partição diminuiu com o aumento da concentração de LI. Rodrigues (2001), observou também esta tendência estudando a partição de $\alpha$-lactalbumina em SAB. Um incremento da concentração de PEG resultou numa diminuição da partição da $\alpha$ lactalbumina para a fase superior.

\section{CONCLUSÃO}

A extração de biomoléculas com a utilização de $\mathrm{SAB}$ compostos por líquidos iônicos é um tanto quanto recente, porém os poucos estudos realizados sobre o assunto comprovam o surgimento de um processo de grande interesse. O efeito da concentração de líquido iônico $\left(\mathrm{C}_{4} \mathrm{minCl}\right)$ na eficiência de extração foi investigado. Resultados experimentais mostraram que $62,5 \%$ de GMP e $98,4 \%$ de $\beta$-lg foram extraídos para a fase superior (rica em LI) indicando que esta nova técnica é promissora para extração de ambas as proteínas. Os valores encontrados dos coeficientes de partição de ambas as proteínas indicaram que as mesmas foram extraídas para fase superior do sistema.

\section{REFERÊNCIAS}

CASSOL, C. C. Líquidos Iônicos em Processos de Extração Seletiva de Compostos Aromáticos, Nitrogenados e Sulfurados em Frações do Petróleo. Dissertação de Mestrado, Universidade Federal do Rio Grande do Sul, Instituto de Química, 2007.

CHEN. J.P. Partitioning and Separation of $\alpha$-lactalbumin and $\beta$-lactoglobulin in PEG/potassium phosphate aqueous two-phase systems. J. of Ferment. Bioengineering, v. 73, n. 2, p. 140147, 1992. 


\section{9 a 22 de outubro de 2014 \\ Florianópolis/SC}

CLÁUdIO, A. F. M.; FREIRE, M. G.; FREIRE, C. S. R.; SILVESTRE, A. J. D.; COUTINHO, J. A. P., extraction of vanillin using ionic-liquid-based aqueous two-phase systems, Sep. Purif. Technol. v.75, p. 39-47, 2010.

DU, Z.; YU, Y. L.; WANG, J. H. Extraction of Proteins from Biological Fluids by use of an Ionic Liquid/Aqueous Two-Phase system. Chem.-Eur. J., v. 13, p. 2130-2137, 2007.

DZIUBA, J., MINKIEWICZ, P. Influence of glycosylation on micelle-stabilizing ability and biological properties of C-terminal fragments of cow's k-casein. Int. Dairy J., v. 6, p. 10171044, 1996.

EL-SALAM, A.M. H., EL-SHIBINY, S., BUCHHEIM, W. Characteristics and potential uses of the casein macropeptide. Int. Dairy J., v. 6, p. 327-341, 1996.

FARIA, E. F.; RODRIGUES, I. C.; BORGES, R. V. Estudo do impacto ambiental gerado nos corpos d'água pelo efluente da indústria de laticínio em Minas Gerais. 2004. 86 f. Dissertação (Especialização em Engenharia Sanitária e Meio Ambiente) - Universidade Federal de Minas Gerais, Belo Horizonte. 2004.

FOX P. F.; McSWEENEY, P. L. H; Dairy Chemistry and Biochemistry, Ireland: Blakie Academic \& Professional, 2001.

IDOTA, T., KAWAKAMI, H., NAKAJIMA, I. Bifidobacterium growth promoting activity effect on $\mathrm{N}$-acetylneuraminic acid containing substances. Biosci. Biotech. Biochem, v. 58, p.1720$1722,1994$.

LIU, Y. YU, Y.L. CHEN M.Z. XIAO. X. Advances in aqueous two-phase systems and applications in protein separation and purification. Canadian Journal on Chemical Engineering and Technology, 2, 2011.

MAGALHAES, K.T.; PEREIRA, M.A.; NICOLAU, A.; DRAGONE, G.; DOMINGUES, L.; TEIXEIRA, J.A.; SILVA, J.B.A.; SCHWAN, R.F. Production of fermented cheese wheybased beverage using kefir grains as starter culture: Evaluation of morphological and microbial variations. Bioresource Technology, v. 101, p.8843-8850, 2010.

MOKHTARANI, B., MORTAHEB, H.R., MAFI, M., AMINI, M.H. Partitioning of $\alpha$-lactalbumin and $\beta$-lactoglobulin in aqueous two-phase systems of polyvinylpyrrolidone and potassium phosphate. J. Elsevier, Chromatography B, p. 721-726, 2011.

MONTEIRO FILHO, E. S. Sistemas aquosos bifásicos: uma alternativa para purificação de biomoléculas e simulação de sistemas líquidos complexos. Ciência \& Tecnologia: FATEC$J B$ (ISSN 2178-9436), Jaboticabal (SP), v. 1, n. 1, p. 33-41, 2010.

NEESER, J.R.; GOLLIARD, M.; WOLTZ, A.; ROUVET, M.; GILLMANN, M.L., GUGGENHEIM, B. In vitro modulation of oral bacterial adhesion to saliva-coated hydroxyapatite beads by milk casein derivatives. Oral Microbiol Immunol, 9, nº 4:193-201, 1994.

NEVES, C. M. S. S. Aqueous Biphasic Systems with Ionic Liquids. Dissertação de Mestrado. Universidade de Aveiro, 2009.

PANDY, S. Analytical applications of room-temperature ionic liquids: A review of recent efforts. Anal. Chim. Acta, v. 556, p. 38-45, 2006.

PEI, Y. JIANJI, W. WU, K. XUAN, X. LU, X. Ionic liquid-based aqueous two-phase extraction of 
selected proteins. Sep. Purif. Technol. v. 64, p. 288-295, 2009.

PERUMALSAMY M., BATHMALAKSHMI A., MURUGESAN T. Experiment and correlation of liquid-liquid equilibria of an aqueous salt polymer system containing PEG6000 + sodium citrate. J. Chem. Eng. Data, v. 52, p. 1186, 2007.

PESSOA Jr., A.; KILIKIAN, B. V. Purificação de Produtos Biotecnológicos. $1^{\mathrm{a}}$ ed. São Paulo: Manole, 2005.

PORTO, L. M.; SANTOS, R. C.; MIRANDA, T. L. S. Determinação das melhores condicoes operacionais do processo de produção da ricota. Boletim CEPPA, v. 23, n. 1, p. 173-182, 2005.

RODRIGUES, L. R. M. Valorização da fracção proteica do soro de leite. 197 f. Dissertação (Mestrado em Biotecnologia) - Universidade do Minho, Braga, Portugal, 2001.

SGARBIERI, V.C. Propriedades fisiológicas-funcionais das proteínas do soro de leite, Revista de Nutrição, v. 17 (4), p. 1-8, 2004.

SILVA, C.A.S., COIMBRA, J.S.R., ROJAS, E.E.G., TEIXEIRA J.A.C. Partitioning of glycomacropeptide in aqueous two-phase systems. J. Process Biochemistry, p. 1213-1216, 2009.

VENTURA, S. P. M.; SOUSA, S. G.; FREIRE, M. G.; LIMA, A. S.; COUTINHO, J. A. P. Design of ionic liquids for lipase purification. J. Chromatogr., B, v. 879, p. 679-2687, 2011.

VENTURA, S.P.M.; NEVES, C.; FREIRE, M.G.; MARRUCHO, I.M.; OLIVEIRA, J.; COUTINHO, J.A.P. Evaluation of anion influence on the formation and extraction capacity of ionic-liquid-based aqueous biphasic systems. J. Physical Chemistry B, v. 113(27), p. 9304-9310, 2009.

WASSERSCHEID, P.; WELTON, T. Ionic liquids in synthesis; Wiley-VCH: Weinheim, Germany, 2003.

WEI, D.; IVASKA, A. Applications of ionic liquids in electrochemical sensors. Analytica Chimica Acta, v. 607(2), p.126-135, 2008.

WELTON, T. Room-temperature ionic liquids. solvents for synthesis and catalysis. Chemical Rev., v.99, p. 2071-2084, 1999.

ZASLAVSKY, B. Y. Aqueous two-phase partitioning. New York: Marcel Dekker, 1995. 